\title{
REPLACEMENT AND COLLECTION: A CORRECTION
}

\author{
NICOLAS D. GOODMAN
}

The argument of [2] is not correct. Specifically, Lemma 7 does not appear to be true in general. It does not seem worthwhile to publish a corrected version of the proof, since Friedman and Ščedrov [1], using a somewhat related argument, have now succeeded in proving the full theorem which eluded me. In the notation of [2], they show that $\mathrm{ZF}^{-}$does not have the set existence property and therefore that $\mathrm{ZFI}$ does not imply the collection axiom.

\section{REFERENCES}

[1] HARVEY M. FrIEDMAN and ANDREJ ŠČEDRov, The lack of definable witnesses and provably recursive functions in intuitionistic set theories, Advances in Mathematics, vol. 57 (1985), pp. 1-13.

[2] Nicolas D. Goodman, Replacement and collection in intuitionistic set theory, this Journal, vol. 50 (1985), pp. 344-348.

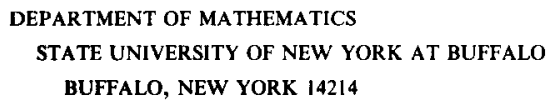

